\title{
Erratum to: Oral Cancer Knowledge and Diagnostic Ability Among Dental Students
}

\author{
Y. Hassona ${ }^{1}$ - C. Scully ${ }^{2}$ N. Abu Tarboush ${ }^{3} \cdot$ Z. Baqain ${ }^{1}$. \\ F. Ismail ${ }^{4} \cdot$ S. Hawamdeh ${ }^{4}$ - F. Sawair ${ }^{1}$
}

Published online: 6 January 2016

(C) American Association for Cancer Education 2016

Erratum to: J Canc Educ (2015)

DOI 10.1007/s13187-015-0958-1

In the above-mentioned article, the author name N. Abu Tarboush was written incorrectly as N. Abutarboosh. However, this error has been already corrected in both the referenced article and in the author listing for this article.

The online version of the original article can be found at doi: http://dx.doi. org/10.1007/s13187-015-0958-1.

Y. Hassona
yazan_hasoneh@yahoo.com

1 Department of Oral and Maxillofacial Surgery, Oral Medicine and Periodontology, Faculty of Dentistry, The University of Jordan, AmmanPO Box 11942, Jordan

2 WHO Collaborating Centre for Oral Health-General Health, University College London, London, UK

3 Department of Physiology and Biochemistry, Faculty of Medicine, The University of Jordan, Amman, Jordan

4 Department of Dentistry, The University of Jordan Hospital, Amman, Jordan 